\title{
An implementation model for production quality management in the Iranian industrial firms
}

\author{
AliReza Amerehei, G. Z. Yuzbashi yeva \\ Industrial Engineering, (Management in Social and Economical Systems), Islamic Azad University, Iran, Komijan
}

Email address:

Amereh@komijani.au.ac.ir (A. Amerehei)

To cite this article:

AliReza Amerehei, G. Z. Yuzbashi yeva. An Implementation Model for Production Quality Management in the Iranian Industrial Firms. International Journal of Economics, Finance and Management Sciences. Vol. 1, No. 6, 2013, pp. 388-390.

doi: $10.11648 /$ j.ijefm.20130106.26

\begin{abstract}
The paper has addressed the various issues of quality growth of industrial production at enterprises of Iran, and studied theoretical approaches to solving these problems, also the problem of choosing the optimal product, improvement of quality circles and departments of quality control on products enterprises, the issues of competitiveness of industrial production (holding market analysis and survey of the market). The articles also shows the international experience in quality management, and its technolioggies may be used in Iran.
\end{abstract}

Keywords: Quality Factor Requires, Customers, Basic needs, Quality Function Deployment

\section{Introduction}

As it is known, improving the quality of goods and services have a defining role in the improvement of competitiveness. It is possible to collect the initial information about any product via price, but the main side of the product is exactly its quality parameters. Thus, the quality is the main driving force of competitiveness for any product type. Glancing at the history, it becomes clear that retail and service settings along with price were considered the main element of competition. However, we should not forget that the competitiveness already means quality for the modern stage.

\subsection{What is Total Quality Management}

It is a popular "quality management" concept. However, it is about much more than just assuring product or service quality. TQM is a business philosophy - a way of doing business. It describes ways to managing people and business processes to ensure complete customer satisfaction at every stage. TQM is often associated with the phrase "doing the right things right, first time". This revision note summarizes the main features of TQM. (Jim Riley, 2012)

\subsection{Quality Factor Require}

1. Quality factor requires the solvation of some issues for the competitiveness, they are as follows:

2. To be aware of the quality in the market and prepare a new plan for reproduction through using this information, and determination of price on this basis

3. To review the services provided to consumers after product sale, to be aware of the costs used for damaged products and their propaganda;

4. To work on how the products works, its durability and outward appearance in order to attract customers;

5. To ensure development and dissemination of a product quality and that the product becomes a good product on the market;

6. To ensure the quality of the product. In other words, if the product is damaged clients must have the minimum expense and loss;

7. Through various advertisements to promote about how the product is produced and its current quality;

8. To prevent all possible major complications that can damage the product prestige.

If to characterize markets within globalization, we can see that production, i.e. offer excels demand in all spheres. It is exactly due to the plentiness of variety of competition and product that markets come acrsoss with instability. Due to the wide variety of choice for consumers who enter the market, therefore the management of the company focuses on the quality factor in order to attract customers. In order to achieve this goal it is necessary to change the whole internal conditions of the enterprise (to conduct the policy of softening for consumer preferences). The main target is 
to produce high-quality product at reasonable prices.

This in turn will help workers to aim at the direction of serving clients. Thus, at the modern stage to produce a high quality product in order to be directed to customer attraction is considered to be the most important principle in the competitive environment.

\subsection{QFD (Quality Function Deployment)}

It is one of the newest quality engineering methods related to market research and promotion of products. In the process of studies recognizing customer needs and preferences enterprises try to use them as an experience in work plan projects for new stages of production. In other words, the economic essence of QFD is to take into account cutomer preferences in order improve the quality of the product at various stages of production. Thus, all projects and plans in the production are prepared on the basis of preferences and ideas of "clients and users".

QFD is a quality method for expanding the product market gaining customer satisfaction. In other words, QFD provides the quality improvement of logical planning process and product. It may also be characterized as a set of a number of chain activities done on the basis of customer satisfaction in order to achieve the ultimate goal.

\section{Methodology}

\subsection{Advantage of QFD Method}

Through this method customer needs are syudied and the obtained information is used in the design of the product. In this process customer preferences are turned into a technical and engineering "language" of the enterprise. With the help of QFD the enterprise is able to accurately take into account customer preferences from the first stage of product processing to the last one. Thus, the efficiency of the product is realized. This process evaluates and determines the quality of various materials at all stages of production. The most significant benefits to use it in industrial enterprises are the followings:

1) To shorten the period of product processing and development (30-50\%);

2) To reduce the number of technical projects change $(25-50 \%)$;

3) To reduce initial costs spent on product

4) To satisfy customers providing their needs and preferences;

5) To increase production intensity;

6) To create compliance in the various divisions of the company;

7) To create a reasonable information center for the next targets.

Customers have their specific role in QFD process. The interrelated and interdependent processes belong not only to the product buyer or employees of economic center, but also to manufacturing and service industry workers.

As it can be seen capital investment, plenty of time and man power are needed to use QFD in product designing. Using old methods resulted in the increase of product cost that caused problems for commodity realization.

\section{Results and Discussions}

As a result, Consumers being devided into segments necessiated certain criteria for the enterprise, that are as follows:

1 To recognize internal and external customers;

2 To precisely perceive customer needs;

3 To always take into account customer needs in projects;

4 To give an exact definition of the product on the basis of customer needs through market finding sections;

5 To make changes that are not intended in the projects after the product enters the market;

6 To accurately determine limitations and abilities of the current process;

7 A single programming during the implementation of projects (to plan after production, sale and after sale services);

8 Detection of cases not planned in product promotion and market entrance (related to project process);

9 related to production requirement adaptation of project proposals;

10 Relations related to work of the enterprise on the basis of customers and their needs;

11 To minimize the number of products returned by customers, reduce warranty costs;

12 The attractiveness of the project and the product development process;

13 To drive employees' attention to the best production in order to learn customer needs.

The main target in QFD project is to find customers for product produced. That is why it is necessary to study different customer groups (segments), product distributors, vendors, after sale employees and other divisions of industrial enterprises, those who are experts in the quality of the product. The main objective of this research is "to hear the voice of the customer". At this stage, in order to use the most important method it is possible to show customer idea in good production, product support, customer complaints, and the behavior of users.

In QFD project the next stage consists of study and analysis of customer needs. At last stratificationa and arrangement of customer needs is considered as one of the next steps in the project. The stratification of customer needs is implemented by QFD group.

Kano model (method) is considered as one of the most spread models in the study of the quality of the product. Dr. Nuryaki Kano as one of the most prominent theorists of quality management devides customer needs, or in other words, product quality in his model into 3 necessary groups:) Basic Needs (QB). According to the feature of the 
first group their implementation in the production prevents only customer dissatisfaction and doesn't cause any special case for customers. In other words, the product (QB) feature provides only its entrance to the market. It doesn't help to get the whole market and succeed over the competitors. This criteria only warranties the durability of the product. B) Abilities (flexibility) need (PQ). The second feature is the product functioning (ability). Otherwise it causes customer dissatisfaction. But if it meets the customer requirements, then gets their satisfaction. Recognition of product functioning (PQ) and implementation reflect maintenance of business position of the enterprise in the market competition. In terms of recognition and clarification these necessities in comparison with other two quality features are very simple and obvious. Therefore, the product features appear in the commercial propaganda, including newspapers, mass media, conversations of friends on a daily basis, which is a kind of a necessity. On the other hand the preferences of this type on the contrary to the first group (reasonable necessities) are such processes that are needed by customers and product users.

To some important means, methods and sources used through studying and finding out necessary needs of customers we may include the following:

1. The preparation of survey booklets;

2. An interview with employees after customers and;

3. An interview with a number of customers by means of an experienced person (Focus Groups);

4. To investigate complaints and shortcomings of the product;

5. To investigate the necessary properties of environmental and cultural conditions;

6. To explore the country's laws and technical standards.

7. C) Targets (objectives) need

In Kano model the third group features are such characteristics that during the processing of the product customer needs are not taken into account that much. Because in an insufficiency that might happen there is no customer dissatifaction. However, the absence of insufficiency on the contrary palys the major role in customer attraction.

The basis of EQ features consist of the accounting of the product in production project and causing reasonable and positive changes in positions of the firm speedly taking the place of other similar products in market competition. Nowadays, giving more priority to quality characteristics in industrial production will end in consumer satisfaction, and this in turn will play a significant role in competitive struggle in order to succeed.

Kano model helps an enterprise as the most efficient method in gathering information from different customer groups. That method, besides studying and analyzing customer needs stratifies product for its durability and helps it to success in market competition.

According to Kano, in today's competitive market paying attention to the needs of the first and second type enterprise may gain "flexibility" in the market in a certain sense. However, it won't be enough to win the competition in the market. Besides that, according to Kano industrial for enetrprises without competitors the quality parameter turns into a second-class position.

The planning of product improvement stages consists of the following:

1 To determine the quality and requests of customers.

In terms of quality the consequence of main issues in studying necessity of primary needs and preferences of customers is as follows:

- $\quad$ to recognize all customer groups;

- $\quad$ in terms of need and preference to precisely gather information from customers;

- To recognize the necessary needs for the improvement of the product by means of using a "Revolting" method;

- to turn basic information into logic data and to use reason graphic in their classification;

- to use "Tree" graphic in order to check the fulfillment of all quality expectations.

\section{Conclusion}

Of course, all demands of customers in terms of value are not the same. In terms of customer and manufacturer a number of them are important. For this reason, it is possible to use it from 1 to 5 in various stratification. In this sphere the most important issue is to use the capabilities of customers and experienced people.

\section{References}

[1] Amerehi,A, 2012. A Management of Product Quality in Industerial Instituion of Iran.

[2] Ishikawa,K, 1984. Quality Control Circles At Work .

[3] Logothetis ,N,1992Managing for Total Quality

[4] Mehraban,R, 2006.Advance product Quality Planning (APQP).

[5] Mike Robson, 1988 . Quality Circles.

[6] Paranthaman ,1987. Quality Control

[7] Razani ,A.M, 1998.Applied T.Q.M Model

[8] Riley,2012. Quality - TQM. Sunday 23 September.

[9] Zomorrodian,A, 1986. Total Quality Management . 